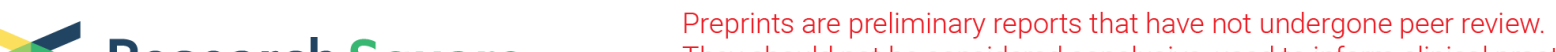 Research Square They should not be considered conclusive, used to inform clinical practice, or referenced by the media as validated information.
}

\section{Clinicopathological Characteristics and Prognosis of Gastric Cancer With Old Tuberculosis: A Propensity Score Matching Analysis}

\section{Meng-Hua Yan ( $\sim 2663407875 @ q q . c o m$ )}

Department of Gastrointestinal Surgery and Laboratory of Gastric Cancer, State Key Laboratory of Biotherapy, West China Hospital, Sichuan University, and Collaborative Innovation Center for Biotherapy, Chengdu, China

\section{Xiao-Hai Song}

Sichuan University West China Hospital

Wei-Han Zhang

Sichuan University West China Hospital

Kai Liu

Sichuan University West China Hospital

Xiao-Long Chen

Sichuan University West China Hospital

Lin-Yong Zhao

Sichuan University West China Hospital

\section{Xin-Zu Chen}

Sichuan University West China Hospital

\section{Kun Yang}

Sichuan University West China Hospital

\section{Bin Song}

Sichuan University West China Hospital

\section{Bing Wu}

Sichuan University West China Hospital

Jian-Kun Hu

Sichuan University West China Hospital https://orcid.org/0000-0001-6905-3934

\section{Research}

Keywords: Gastric cancer, Old pulmonary tuberculosis, Overall survival, Postoperative pulmonary complications

Posted Date: September 16th, 2020 
DOI: https://doi.org/10.21203/rs.3.rs-75477/v1

License: (c) (1) This work is licensed under a Creative Commons Attribution 4.0 International License. Read Full License 


\section{Abstract}

Background: It is known that Bacillus Calmette-Guérin (BCG), which serves as an adjuvant immunotherapy, has certain beneficial effects on the prognosis for gastric cancer. However, no existing reports have probed into the impact of old tuberculosis (TB) lesion on patients with gastric cancer.

Methods: Using the database from a high-volume center, 2649 consecutive gastric cancer patients admitted to West China Hospital undergoing curative-intent gastrectomy were identified between 2009 and 2016. Patients were divided into TB group and non-tuberculosis (NTB) group based on the presence or absence of a coexistent old pulmonary TB lesion. Then, multinomial logistic regression models tested the risk factors for the postoperative pulmonary complications (PPCs). Kaplan-Meier analyses and Cox regression models tested the effect of old TB lesion on overall survival (OS) rate. The propensity scorematching (PSM) method was used to assemble a well-balanced cohort.

Results: Altogether 81 of the enrolled patients had old pulmonary TB lesions. The presence of an old TB lesion was associated with superior overall survival (OS). Besides, the 3-year OS rates were $84.7 \%$ in TB group and $69.2 \%$ in NTB group, and the difference between two groups was statistically significant $(p=0.005)$. Similarly, in the following analysis on 73 pairs of matched patients, significant differences were also noted between the two cohorts $(p=0.001)$, with the 3-year OS rates of $90.4 \%$ and $69.2 \%$, respectively. Further, multivariable Cox regression analysis showed that old TB was an independent positive factor for OS before and after propensity score-matching (PSM) $(p=0.002 / p<0.001$, $\mathrm{HR}=0.471 / 0.220$, respectively). Additionally, the old TB lesion appeared to be an independent risk factor for postoperative pulmonary complications (PPCs) (both $p<0.001, \mathrm{HR}=3.375$ and $\mathrm{HR}=3.415$ in univariate and multivariate logistic regression, respectively).

Conclusions: Old TB lesion is a risk factor for PPCs. Despite that, it represented as an independent positive factor for the prognosis of gastric cancer in general. This study may shed light on further immune therapy for gastric cancer.

\section{Introduction}

Gastric cancer and tuberculosis (TB) are the two major health problems worldwide. TB remains a major cause of ill health despite the technological and therapeutic advances, and the number of TB cases is estimated to be 10.0 million in 2018 [1]. Typically, gastric cancer is the fifth most common cancer and the third leading cause of cancer death worldwide [2]. Given that both gastric cancer and TB possess a substantial impact on public health, the association between these two epidemics deserves further investigation.

The relationship between gastric cancer and TB has always been a hot topic for decades. In the 20th century, several clinical trials report that using the Bacillus Calmette-Guérin (BCG), a vaccine derived from mycobacterial tuberculosis, as an adjuvant non-specific immune potentiator can prolong the survival of gastric cancer patients [3-5]. Particularly, in recently years, immunotherapy seems promising 
for gastric cancer in monotherapy or in combining strategies, which has revolutionized the oncology landscape by targeting the host immune system [6]. For instance, blocking immune checkpoints such as cytotoxic T-lymphocyte-associated antigen 4 (CTLA-4), programmed cell death-1 (PD-1) and its ligand (PD-L1 or B7-H1), has proven efficacy in several solid cancers [7]. Whether old healed TB play a role in the outcomes of gastric cancer patients via some immunotherapy ways like BCG remains unclear.

Considering the fact that no existing study has investigated the impact of old TB lesion on the clinicopathological characteristics and prognosis of gastric cancer, this study aimed to explore the impact of old healed TB lesion on the survival and clinicopathological features of gastric cancer patients based on the surgical outcomes from a high-volume center in Southwest China.

\section{Materials And Methods}

\section{Study design and patient population}

Patient baseline information was gathered from the Surgical Gastric Cancer Patient Registry database in West China Hospital (registration number, WCH-SGCPR-2020-04). The database was established under the approval of the Research Ethics Committee of West China Hospital, Sichuan University, China. Informed consent was waived due to the retrospective nature of this study. However, patient records were deidentified and anonymized before statistical analysis.

A total of 2649 patients who underwent radical cystectomy for gastric cancer were retrospectively collected from West China Hospital of China from January 1st, 2009 to December 31st, 2016. The survival outcomes of these patients were followed up for at least 3 years after surgery. The study flowchart is presented in Fig. 1. The patient inclusion criteria were as follows: (1) those with histologically confirmed adenocarcinoma of the stomach; and (2) those who underwent curative-intent surgery. Meanwhile, patients conforming to any one of the following criteria were excluded from this study: (1) those with carcinoma of the remnant gastric; (2) those who received R1 or R2 surgery; (3) those with other malignancies in stomach; (4) those received previous chemotherapy and/or radiation therapy; (5) those with other malignancies prior to the operation; and (6) those with incomplete medical records. Complete preoperative examinations, including physical examination, gastroscopic biopsies, chest X-ray or computer tomography (CT) scans, abdomen enhanced CT scans, pulmonary function and heart Doppler ultrasound, were given to all patients. Surgical treatments were comprised of surgical procedures (total gastrectomy, distal gastrectomy, proximal gastrectomy), the extent of lymphadenectomy (D1, D1+, D2, D2+), and the surgical approaches (open gastrectomy, laparoscopic gastrectomy, robot-assisted gastrectomy) in line with the Japanese Gastric Cancer Treatment Guidelines at the time of surgery. Scheduled adjuvant therapies, including chemotherapy and radiotherapy, were adopted based on the suggestions by medical oncologists and the wills of patients themselves. Follow-up information was obtained at intervals of 6 months by follow-up visits. Other follow-up approaches included outpatient visits, telephone interviews, network tools and letters. Among the 2649 patients, 411 (16.0\%) in non- 
tuberculosis group (NTB) group and 4 (4.9\%) in TB group were lost to follow-up, yielding the overall follow-up rate of $84.3 \%$ in our cohort.

\section{Definitions}

The fibronodular lesions, fibrotic changes, calcified nodules, pleural thickening, and scars present on chest X-ray or CT were regarded as the old TB lesions [8]. Meanwhile, patients with a past medical history were also considered to have old TB lesions. After reviewing the chest films, two qualified reviewers made a final diagnosis by consensus.

Postoperative complications (POCs) were defined as any deviation from an uneventful postoperative course within 30 days of the operation according to the Clavien-Dindo classification [9]. Postoperative pulmonary complications (PPCs) were defined as a composite of respiratory failure, pleural effusion, atelectasis, pulmonary infection, pneumothorax and bronchospasm within 7 days postoperatively, as suggested in the previously published articles [10][11].

Clinical evaluations: TNM stage, histopathological grading, residual tumor (R) classification and Bormann type were evaluated by the UICC TNM classification(7th edition) [12]. Performance status was evaluated by ECOG (Eastern Cooperative Oncology Group) [13].

\section{Propensity score matching (PSM)}

To create the well-balanced cohorts, PSM was performed to minimize the effect of selection bias and to control the confounding factors in survival analysis. In this study, PSM was conducted using the greedy nearest-neighbor matching of 1:2 without replacement, with a caliper width of 0.10 of the propensity score logit. Each patient in TB group was matched by all the important baseline variables to two patients in NTB group.

\section{Statistical analysis}

Cohort baseline characteristics were described as categorical variables and presented as counts and percentages, or as continuous variables and expressed as median and range. Chi-square test or Fisher's exact test was employed to compare the categorical variables, while Wilcoxon rank sum test was performed to compare the continuous data.

Overall survival (OS) was defined as the interval from the date of surgery to the date of death or the last follow-up on December 31st, 2019. Multinomial logistic regression models were utilized to test the risk factors for PPCs. Any differences in survival were evaluated with log-rank test. Moreover, Cox proportional hazards models were fitted to test the prognostic factors for OS. Besides, the clinically relevant candidate variables or those with a $p$-value $<0.1$ upon univariate analysis were incorporated into the multivariate logistic or Cox regression model. The Stata (version 14.0, Stata Corp) was employed for statistical analysis. The significance level was set at $p<0.05$. 


\section{Results}

\section{Patient demographics}

From January $1^{\text {st }}, 2009$ to December $31^{\text {st }}, 2016$, altogether 2649 pathologically confirmed incident gastric adenocarcinoma cases were enrolled into our cohort. Detailed information of patient clinicopathological characteristics are presented in Table 1. The short-term endpoints and survival outcome were depicted in Table 2. The median age at the time of diagnosis was 59 (range, 21-86) years.

There were 2568 patients in NTB group and 81 in TB group, respectively. As discovered from Table 1 and Table 2, there were some heterogeneities in baseline characteristics between the two groups. To be specific, TB group was associated with a higher proportion of male patients, prior pulmonary comorbidities, ex-smoker or current smoker, PPCs and a smaller tumor size and shorter PODs. In addition, significant differences were also observed in the distributions of pathological stages and Bormann types. Furthermore, PSM was performed to create the comparable groups. After PSM, all variables between 142 cases in NTB group and 73 in TB group revealed equal distributions of patient demographics and baseline characteristics (Table 1, Table 2, $p>0.05$ for all).

\section{POCs and baseline factors}

POCs between cohorts revealed some different distributions. In detail, significant differences were observed in the distribution of PPCs between cohorts, with the PPCs occurrence in $262(10.2 \%)$ patients in the NTB group and $22(27.2 \%)$ patients in the TB group. We further performed the univariate and multivariate logistic regression analysis to assess the risks for PPCs. The univariate analysis revealed that old TB, older age, higher ECOG score, ex-smoker or current smoker, comorbidities, perioperative blood transfusions, surgical procedure, lower third location and poorly differentiated histology (G3) were significantly associated with PPCs ( $p<0.05$ for all, Table 3 ). After the multivariate logistic regression analysis, TB history, older age, pulmonary dysfunction, lower third location remained to be risk factors for PPCs $(p<0.05$ for all, Table 3$)$.

\section{Survival}

Upon the last follow-up, 1003 out of the 2649 patients (39.1\%) died, with a median OS time of 22.1 months. Meanwhile, 940 of the 1021 deaths (93.7\%) were related to cancer. The median OS time since operation for all patients was 50.1 months, and the overall 1- and 3-year OS rates were $91.5 \%$ and $72.2 \%$, respectively. There were significant differences in OS between the two cohorts (Fig.2a). The estimated 3year OS rate in TB group was $84.7 \%$, which was significantly higher than that of $69.2 \%$ in NTB group $(p=0.005$; Fig.2a). The median follow-up period in TB group was 57 months, about 7 months longer than that in NTB group (50 months, $p=0.011)$.

After one-to-two PSM, 73 pairs of patients were qualified for further analysis. Good balance was demonstrated for both of the matched patients, with no clinically significant differences in the covariates, 
as depicted in Table 1 and Table 2. Besides, significant differences in OS rates were also detected in the PSM cohorts (Fig.2b). The 3-year OS rate in TB group was $90.4 \%$, which was higher than that of $69.2 \%$ in NTB group ( $p=0.001$; Fig. $2 \mathrm{~b}$ ). After adjusting for potential confounders by multivariate Cox regression analysis, the coexistence of old TB lesion remained significantly and strongly associated with the decreased tumor-related mortality (adjusted HR: 0.220, [95\% Cl: 0.107-0.454], $p<0.001$ ), as shown in Table 5 .

\section{Univariate and Multivariate Cox Regression}

In univariate analysis, old TB, age, ECOG score, pulmonary dysfunctions, perioperative blood transfusions, tumor size, surgical procedure, surgical approach, lower third and diffused locations, histological grading, neural/vascular invasion, Bormann's type, pathological T-N-M category, pathological TNM stage, POCs and adjuvant chemotherapy were associated with the patient's OS (Table 4). Based on univariate analysis results, factors of TB history, age, ECOG score, comorbidities, blood transfusions, tumor size, surgical procedure, approach, location, histological grading, Bormann's type, neural/vascular invasion, T-N-M stage, POCs and adjuvant chemotherapy were included for stepwise multivariate Cox regression analysis. It was discovered that old TB lesion and adjuvant chemotherapy were the independent factors to determine good survival, while older age, pulmonary dysfunctions, blood transfusion, bigger tumor size, diffused location, higher TNM classifications, PPCs predicted poor prognosis (Table 4).

After PSM, old TB, tumor size, blood transfusion, surgical procedure, location, Bormann type, T-N-M category, P-stage, PPCs and adjuvant chemotherapy were identified to be associated with OS in the univariate analysis. Stepwise analysis of the multivariate Cox regression included the same covariates as in the multivariate analysis before PSM. And finally, several independent positive prognosticators for OSold TB, adjuvant chemotherapy, proximal gastrectomy and laparoscopic or robot-assisted gastrectomy, and several negative prognosticators including middle third or lower third locations and G3 and PPCs were identified after PSM. Detailed univariate and multivariate Cox regression analyses of OS after PSM are shown in Table 5.

\section{Discussion}

To the best of our knowledge, this study is by far the first cancer series that demonstrates the influence of a pulmonary TB history on the clinicopathological characteristics and prognosis of gastric cancer patients. According to our results, Old TB lesion is a risk factor for PPCs. Despite that, it represented as an independent positive factor for the prognosis of gastric cancer in general.

Our findings were consistent with a previous work reporting that post-TB lesion was an independent risk factor for PPCs. The impacts of old TB on pulmonary impairment, which usually manifest as restrictive dysfunction, obstructive dysfunction or both, have been extensively acknowledged in previous literature [14][15]. Furthermore, a prospective study by Eun Sun Kim et al [16]. on patients with non-small-cell lung cancer (NSCLC) revealed that, the presence of old TB lesion on chest X-ray radiograph was an 
independent risk factor for PPCs. Our findings were similar to the previous results. The possible explanation may be the destructive and fibrosing properties of pulmonary TB, which cause pulmonary impairment [17], thus contributing to the increased incidence of PPCs compared with patients without a prior TB. Additionally, multivariable Cox regression analysis suggested that PPCs was the independent risk factor significantly associated with the poor outcomes of gastric cancer, consistent with a previous study [18]. These results suggest that special attentions should be paid to the perioperative respiratory management of the special group.

As for the positive effect of old TB on the survival of gastric cancer, the possible explanations are elaborated below. Firstly, old TB possibly improves the survival of gastric cancer patients by the same way as BCG. BCG has once been used as a nonspecific immunotherapy to treat cancer, but it is largely abandoned later due to a lack of persistent effects. Even so, evidence from several clinical trials has indicated that BCG immunotherapy prolongs the survival time of gastric cancer patients. Although the precise mechanisms underlying the beneficial effects of BCG remain unclear so far, it is possible that the following factors may be involved, including the production of tumor necrosis factor (TNF)-alpha and other antitumor cytokines, as observed in bladder cancer [19], the enhancement of monocyte- and lymphocyte-mediated tumor cell-killing synergism [20], or the tolerance to chemotherapy [21]. Secondly, one research on mycobacterial TB product heparin-binding hemagglutinin ( $\mathrm{HBHA}$ ) unravels that $\mathrm{HBHA}$, as an immunostimulant, can lyse tumor cells and suppress tumor growth by stimulating dendritic cells (DCs), which thereby further activate the T cell-mediated tumor cell killing [22]. Additionally, another study documents the anti-cancer activity of Mycobacterium indicus pranii $(\mathrm{Mw})$ in melanoma, which shares the same antigen with mycobacterial TB [23]. Mw modifies MMP-9 expression in murine macrophages in vitro [24], thus defending against the migration and invasion of melanoma. It is reported that after TB infection, granulomas that contain quiet M. TB antigen and soluble pathogen contribute to the persistent memory of adaptive immune response [25], which may play its antitumor effects [26]. Therefore, it is reasonable to assume that adaptive immune response may exert the anti-cancer effects via TNF, DCs, T cells (especially the activated CTLs and Th1 cells), and some other potential ways, as implicated in the above studies.

In this study, it was noticed that several similar studies investigating the impacts of TB on the survival of lung cancer patients reported contradictory findings. For instance, Kuo and coworkers [27] suggested that NSCLC patients with active TB showed better survival outcomes, and the effective T lymphocyte infiltration in tumor might be the underlying mechanism. Chia-Hao Chang et al. [28] reported that previous TB had a gender-dependent impact on lung cancer, with better 1-year progression-free survival (PFS) in female patients but worse PFS in male patients. In this case, the differences in carcinogenesis and inflammation between male and female patients might account for the related mechanisms. Contrarily, several studies show that old TB is negatively associated with the survival of lung cancer patients [29] [30]. For example, a previous study has indicated that old pulmonary TB is an independent risk factor for PPCs [16], which is also related to a poorer long-term outcome, with a 6-month reduction in the mean OS of lung cancer [31]. Thus, it was hypothesized that the prognostic effect of old TB on lung cancer patients might be confounded by PPCs, which were not included as a confounding factor in the analysis of all the 
above studies. In our study, it was found that old pulmonary TB was a protective factor for the OS of gastric cancer, but a risk factor for PPCs. Despite the higher incidence of PPCs in TB group and the negative effect on prognosis brought by PPCs, this study showed that old pulmonary TB still represented a favorable factor for the OS of gastric cancer. It is hypothesized that the overwhelming protective effect, which is contributed by old TB, may interpret the improved prognosis of gastric cancer patients.

In particular, 11 patients in our cohort had concurrent perigastric lymph node TB, of them, 6 cases without old pulmonary TB were assigned to NTB group. In view of the small sample size and the minimal heterogeneity in TB group, the 11 cases with lymph node TB were not analyzed separately in earlier analysis. These 11 patients had relatively early $\mathrm{N}$ stages (including 6 at N0, 4 at $\mathrm{N} 1$ and 1 at N2) and pathological TNM stages (including 5 at stage I, 4 at stage II, 1 at stage III and 1 at stage IV). The median OS for these 11 patients was 71.2 (range, 34.7-129.7) months, and the 3-year OS rate was $81.8 \%$ (95\% Cl: 44.7-95.1). Our findings were consistent with a previous study reporting that gastric cancer patients with tumor-related sarcoid granuloma reactions in regional lymph nodes had favorable prognosis [32]. As far as we know, this is the first study to illustrate the positive effect of perigastric lymph node TB on pathological patterns and prognosis. Typically, the protective effect of perigastric lymph node TB may be best explained by the effective T lymphocyte infiltration in tumor, as mentioned previously. Moreover, earlier studies have discovered that latent pulmonary TB can transport to regional lymph node and disseminate via the bloodstream [33]. No matter which body part they reach, the microorganisms may gain entry into epithelial cells and fibroblasts, or are engulfed by the local tissue macrophages. This usually elicits a low-grade inflammatory response and attracts the antigen-responding T-and B-cells. Hence, it is reasonable to believe that the inflammatory response possibly inhibits the migration of gastric cancer.

Certain limitations should be noted in this study. First, as a retrospective cohort study, the inherent nature determines its diminishing ability to determine causality. However, this study is a relatively large series of gastric cancer patients with a prior history of TB, and it is unlikely that large-scale prospective randomized trials will be organized, since gastric cancer concurrent with old healed TB is rare. Second, it is notable that some misclassification of exposure can not be exclude due to the self-report of TB. Not all subjects may remember their TB, or they may be unaware that they have had TB in the past. Thirdly, despite the relatively considerable sample size in a single center, it may still be too small to generalize to the entire population. Thereby, multi-center studies and/or prospective studies are warranted to verify the putative positive effect of old TB.

In conclusion, old TB lesion is a favorable prognostic factor for the survival of gastric cancer patients, but a risk factor for PPCs as well. Our study shed light on further immune therapy study for gastric cancer. Of course, attentions should also be paid to this special group. Due to the small sample size in our study, replication of our findings in other cohorts is warranted. Apart from epidemiological studies, more research is needed to elicit the potential immunological links between TB and gastric cancer.

\section{Abbreviations}


BCG Bacillus Calmette- Guérin

CTLA-4 Cytotoxic T-lymphocyte-associated antigen 4

PD-1 Programmed cell death-1

TB Tuberculosis

NTB Non-tuberculosis

PPCs Postoperative pulmonary complications

OS Overall survival

PSM Propensity score-matching

$\mathrm{Cl} \quad$ Confidence Interval

HR Hazard Ratio

POD Postoperative days

CT Computer tomography

POCs Postoperative complications

R Residual tumor

G1 Well differentiated

G2 Moderately differentiated

G3 Poorly differentiated

ECOG Eastern Cooperative Oncology Group

BMI Body Mass Index

NSCLC Non-small-cell lung cancer

TNF Tumor necrosis factor

HBHA Heparin-Binding Hemagglutinin

DCs Dendritic cells

Mw Mycobacterium indicus pranii 
PFS Progression-free survival

\section{Declarations}

\section{Acknowledgements}

The authors thank the substantial work of the Volunteer Team of Gastric Cancer Surgery (VOLTGA) based on the Multidisciplinary Team (MDT) of Gastrointestinal Tumors, West China Hospital, Sichuan University, China.

\section{Author's Contributions}

Meng-Hua Yan and Xiao-Hai Song: study design, data analysis and paper writing. Kai Liu, Xiao-Long Chen, Bin Song and Bing Wu: data collection. Xiao-Long Chen, Lin-Yong Zhao, and Kun Yang: patient follow-up. Wei-Han Zhang and Xin-Zu Chen: database establishment. Jian-Kun Hu: supervision and paper revision. The authors read and approved the final manuscript. All authors contributed to the writing of the manuscript and final approval.

\section{Funding Sources}

1) Sichuan Science and Technology Program (No.2019YFS0255).

2) 1.3.5 project for disciplines of excellence, West China Hospital, Sichuan University (ZY2017304).

3) China Postdoctoral Science Foundation, No. $2015 \mathrm{M} 58079$.

\section{Availability of data and materials}

The data that support the results of this research is available on request from the corresponding author. Considering privacy or ethical restrictions, the data is not publicly available.

\section{Ethics approval and consent to participate}

Patient records were de-identified and anonymized prior to the analysis. The Research Ethics Committee of West China Hospital approved this retrospective study, and the Surgical Gastric Cancer Patient Registry number was No. WCH-SGCPR-2020-04.

\section{Consent for publication}

Not applicable.

\section{Competing interests}

The authors declare that they have no conflict of interest. 


\section{References}

1. World Health Organization. Global tuberculosis report 2019. Geneva: World Health Organization; 2019.

2. Bray F, Ferlay J, Soerjomataram I, et al. Global cancer statistics 2018: GLOBOCAN estimates of incidence and mortality worldwide for 36 cancers in 185 countries. Cancer J Clin. 2018;68(6):394424.

3. Nakazato H, Koike A, Saji S, et al. Efficacy of immunochemotherapy as adjuvant treatment after curative resection of gastric cancer. The Lancet. 1994;343(8906):1122-6.

4. Popiela T, Kulig J, Czupryna A, et al. Efficiency of adjuvant immunochemotherapy following curative resection in patients with locally advanced gastric cancer. Gastric Cancer. 2004;7(4):240-5.

5. Popiela T, Zembala M, Oszacki J, et al. A follow-up study on chemoimmunotherapy (5-fluorouracil and BCG) in advanced gastric cancer. Cancer Immunol Immunother. 1982;13(3):182-4.

6. Coutzac $\mathrm{C}$, Pernot $\mathrm{S}$, Chaput $\mathrm{N}$, et al. Immunotherapy in advanced gastric cancer, is it the future? [J]. Crit Rev Oncol/Hematol. 2019;133:25-32.

7. Ribas A, Wolchok JD. Cancer immunotherapy using checkpoint blockade[J]. Science. 2018;359(6382):1350-5.

8. Lee KS, Im JG. CT in adults with tuberculosis of the chest: characteristic findings and role in management. AJR Am J Roentgenol. 1995;164(6):1361-7.

9. Dindo D, Demartines N, Clavien PA. Classification of surgical complications: a new proposal with evaluation in a cohort of 6336 patients and results of a survey. Annals of surgery. 2004;240(2):205.

10. Jeong BH, Shin B, Eom JS, et al. Development of a prediction rule for estimating postoperative pulmonary complications. PloS one, 2014, 9(12).

11. Canet J, Gallart L, Gomar C, et al. Prediction of postoperative pulmonary complications in a population-based surgical cohort. Anesthesiology: The Journal of the American Society of Anesthesiologists. 2010;113(6):1338-50.

12. Sobin LH, Gospodarowicz MK, Wittekind C. TNM classification of malignant tumors. John Wiley \& Sons, 2011.

13. Oken MM, Creech RH, Tormey DC, et al. Toxicity and response criteria of the Eastern Cooperative Oncology Group. Am J Clin Oncol. 1982;5(6):649-56.

14. Lee SW, Kim YS, Kim DS, et al. The risk of obstructive lung disease by previous pulmonary tuberculosis in a country with intermediate burden of tuberculosis. J Korean Med Sci. 2011;26(2):268-73.

15. Pasipanodya JG, Miller TL, Vecino M, et al. Pulmonary impairment after tuberculosis. Chest. 2007;131(6):1817-24.

16. Kim ES, Kim YT, Kang CH, et al. Prevalence of and risk factors for postoperative pulmonary complications after lung cancer surgery in patients with early-stage COPD. Int J Chronic Obstr Pulm Dis. 2016;11:1317. 
17. Snider GL, Doctor L, Demas TA, et al. Obstructive airway disease in patients with treated pulmonary tuberculosis. American review of respiratory disease. 1971;103(5):625-40.

18. Lawrence VA, Hilsenbeck SG, Mulrow CD, et al. Incidence and hospital stay for cardiac and pulmonary complications after abdominal surgery. J Gen Intern Med. 1995;10(12):671-8.

19. Fujimoto T, Duda RB, Szilvasi A, et al. Streptococcal preparation OK-432 is a potent inducer of IL-12 and a T helper cell 1 dominant state. J Immunol. 1997;158(12):5619-26.

20. Pryor K, Goddard J, Goldstein D, et al. Bacillus Calmette-Guerin (BCG) enhances monocyte-and lymphocyte-mediated bladder tumour cell killing. British journal of cancer. 1995;71(4):801-7.

21. Zembala M, Czupryna A, Wieckiewicz J, et al. Tumour-cell-induced production of tumour necrosis factor by monocytes of gastric cancer patients receiving BCG immunotherapy. Cancer Immunol Immunother. 1993;36(2):127-32.

22. Jung ID, Jeong SK, Lee CM, et al. Enhanced efficacy of therapeutic cancer vaccines produced by cotreatment with Mycobacterium tuberculosis heparin-binding hemagglutinin, a novel TLR4 agonist. Can Res. 2011;71(8):2858-70.

23. Gupta A, Geetha N, Mani J, et al. Immunogenicity and protective efficacy of "Mycobacterium w" against Mycobacterium tuberculosis in mice immunized with live versus heat-killed $M . w$ by the aerosol or parenteral route. Infect Immun. 2009;77(1):223-31.

24. Halder K, Banerjee $\mathrm{S}$, Ghosh $\mathrm{S}$, et al. Mycobacterium indicus pranii (Mw) inhibits invasion by reducing matrix metalloproteinase (MMP-9) via AKT/ERK-1/2 and PKCa signaling: A potential candidate in melanoma cancer therapy. Cancer Biol Ther. 2017;18(11):850-62.

25. Flynn JAL, Chan J. Immunology of tuberculosis. Annu Rev Immunol. 2001;19(1):93-129.

26. Maus MV, Fraietta JA, Levine BL, et al. Adoptive immunotherapy for cancer or viruses[J]. Annu Rev Immunol. 2014;32:189-225.

27. Kuo CH, Lo CY, Chung FT, et al. Concomitant active tuberculosis prolongs survival in non-small cell lung cancer: a study in a tuberculosis-endemic country. PloS one, 2012, 7(3).

28. Chang $\mathrm{CH}$, $\mathrm{Lee} \mathrm{CH}, \mathrm{Ho} \mathrm{CC}$, et al. Gender-based impact of epidermal growth factor receptor mutation in patients with nonsmall cell lung cancer and previous tuberculosis. Medicine, 2015, 94(4).

29. Heuvers ME, Aerts JGJV, Hegmans JP. History of tuberculosis as an independent prognostic factor for lung cancer survival. Lung Cancer. 2012;76(3):452-6.

30. Zhou Y, Cui Z, Zhou X, et al. The presence of old pulmonary tuberculosis is an independent prognostic factor for squamous cell lung cancer survival. Journal of Cardiothoracic surgery. 2013;8(1):123.

31. Lugg ST, Agostini PJ, Tikka T, et al. Long-term impact of developing a postoperative pulmonary complication after lung surgery. Thorax. 2016;71(2):171-6.

32. Kurata A, Terado Y, Schulz A, et al. Inflammatory cells in the formation of tumor-related sarcoid reactions. Human pathology. 2005;36(5):546-54. 
33. Hernandez-Pando R, Jeyanathan M, Mengistu G, et al. Persistence of DNA from Mycobacterium tuberculosis in superficially normal lung tissue during latent infection. The Lancet. 2000;356(9248):2133-213.

\section{Tables}

Table 1 Baseline characteristics and propensity score-matched baseline characteristics between group TB (patients with old TB) and group NTB (patients without old TB) 


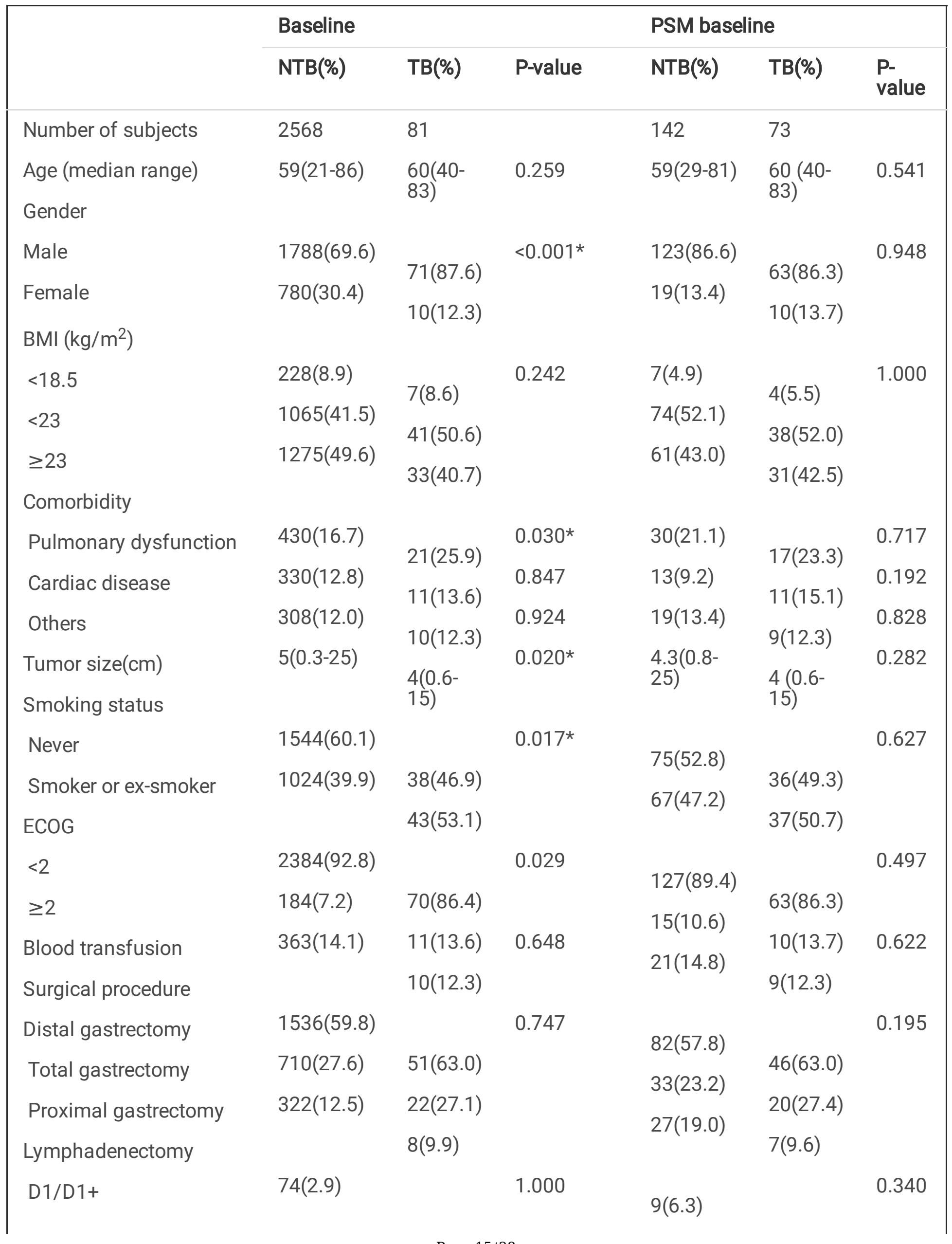




\begin{tabular}{|c|c|c|c|c|c|c|}
\hline D2/D2+ & 2494(97.1) & $2(2.5)$ & & 133(93.7) & $2(2.7)$ & \\
\hline Approach & & 79(97.5) & & & 71(97.3) & \\
\hline Open gastrectomy & 2226(86.7) & & 0.564 & 118(83.1) & & 0.378 \\
\hline LG/RAG & $342(13.3)$ & $72(88.9)$ & & $24(16.9)$ & $64(87.7)$ & \\
\hline Location & & $9(11.1)$ & & & $9(12.3)$ & \\
\hline Upper third & $633(24.7)$ & & 0.850 & $37(26.0)$ & & 0.431 \\
\hline Middle third & $315(12.3)$ & 17(21.0) & & $15(10.6)$ & 15(20.5) & \\
\hline Lower third & 1557(60.6) & $10(12.4)$ & & $86(60.6)$ & 10(13.7) & \\
\hline Diffused & $63(2.4)$ & $53(65.4)$ & & $4(2.8)$ & $48(65.8)$ & \\
\hline Retrieved nodes & & $1(1.2)$ & & & $0(0)$ & \\
\hline$<15$ & $245(9.5)$ & & 0.786 & $15(10.6)$ & & 0.823 \\
\hline$\geq 15$ & 2323(90.5) & $7(8.6)$ & & $127(89.4)$ & $7(9.6)$ & \\
\hline Histological grading & & 74(91.4) & & & $66(90.4)$ & \\
\hline $\mathrm{G} 1 / \mathrm{G} 2$ & $983(38.3)$ & & 0.821 & $60(42.2)$ & & 0.722 \\
\hline G3 & $1585(61.7)$ & $30(37.0)$ & & $82(57.8)$ & 29(39.7) & \\
\hline Neural/vascular invasion & & $51(63.0)$ & & & $44(60.3)$ & \\
\hline Absent & 2081(81.0) & & 0.117 & $115(81.0)$ & & 0.235 \\
\hline Present & $487(19.0)$ & $60(74.1)$ & & $27(19.0)$ & $54(74.0)$ & \\
\hline Bormann's type & & $21(25.9)$ & & & $19(26.0)$ & \\
\hline Early-stage cancer & $527(20.5)$ & & $0.024^{*}$ & $33(23.2)$ & & 0.354 \\
\hline Type I & $75(2.9)$ & $20(24.7)$ & & $6(4.2)$ & 19(26.0) & \\
\hline Type II & $974(37.9)$ & $7(8.6)$ & & $48(33.8)$ & $7(9.6)$ & \\
\hline Type III & $827(32.2)$ & $22(27.2)$ & & $44(31.0)$ & $19(26.0)$ & \\
\hline Type IV & $165(6.4)$ & $29(35.8)$ & & $11(7.8)$ & 25(34.3) & \\
\hline pT & & $3(3.7)$ & & & $3(4.1)$ & \\
\hline $\mathrm{T} 1$ & $527(20.5)$ & & 0.586 & $33(23.3)$ & & 0.776 \\
\hline T2 & $393(15.3)$ & $20(24.7)$ & & $30(21.1)$ & 19(26.0) & \\
\hline T3 & $504(19.6)$ & 14(17.3) & & 23(16.2) & 14(19.2) & \\
\hline \multirow{2}{*}{ T4 } & $1144(44.6)$ & $17(21.0)$ & & $56(39.4)$ & 15(20.6) & \\
\hline & & $30(37.0)$ & & & $25(34.2)$ & \\
\hline
\end{tabular}




\begin{tabular}{|lllllll|} 
pN & $837(32.6)$ & & 0.714 & $57(40.1)$ & & 1.000 \\
N0 & $437(17.0)$ & $30(37.1)$ & & $24(16.9)$ & $29(39.7)$ & \\
N1 & $474(18.5)$ & $16(19.7)$ & & $24(16.9)$ & $13(17.8)$ & \\
N2 & $526(20.5)$ & $15(18.5)$ & & $25(17.6)$ & $12(16.5)$ & \\
N3a & $294(11.4)$ & $13(16.1)$ & & $12(8.5)$ & $13(17.8)$ & \\
N3b & & $7(8.6)$ & & & $6(8.2)$ & \\
Metastasis & $2442(95.1)$ & & 0.064 & $133(93.7)$ & & 0.886 \\
M0 & $126(4.9)$ & $73(90.1)$ & & $9(6.3)$ & $68(93.2)$ & \\
M1 & & $8(9.9)$ & & & $5(6.8)$ & \\
P-stage & $636(24.8)$ & & $0.033^{*}$ & $43(30.3)$ & & 1.000 \\
Stage I & $596(23.2)$ & $23(28.4)$ & & $43(30.3)$ & $22(30.1)$ & \\
Stage II & $1210(47.1)$ & $23(28.4)$ & & $47(33.1)$ & $22(30.1)$ & \\
Stage III & $126(4.9)$ & $27(33.3)$ & & $9(6.4)$ & $24(32.9)$ & \\
Stage IV & $1051(40.9)$ & $8(9.9)$ & 0.681 & $61(43.0)$ & $5(6.9)$ & 0.945 \\
Adjuvant chemotherapy & & $35(43.2)$ & & & $31(42.5)$ & \\
\hline
\end{tabular}

$T B$, tuberculosis; $N T B$, non-tuberculosis; $B M I$, body-mass index; $E C O G$, Eastern Cooperative Oncology Group; $L G$, laparoscopic gastrectomy; $R A G$, robot-assisted gastrectomy; $G 1$, well differentiated; $G 2$, moderately differentiated; $G 3$, poorly differentiated

$\star P<0.05$, statistical significance

Table 2 Postoperative endpoints and survival outcome before and after PSM between cohorts 


\begin{tabular}{|lllllll|}
\hline Endpoints & \multicolumn{7}{l}{ Baseline } & & \multicolumn{5}{l|}{ PSM baseline } \\
\cline { 2 - 7 } & NTB(\%) & TB(\%) & P-value & NTB(\%) & TB(\%) & P-value \\
\hline $\begin{array}{l}\text { Postoperative } \\
\text { complications }\end{array}$ & $262(10.2)$ & $22(27.2)$ & $<0.001^{*}$ & $27(19.0)$ & $15(20.6)$ & 0.964 \\
$\begin{array}{l}\text { Pulmonary } \\
\text { complications }\end{array}$ & $256(10.0)$ & $8(9.9)$ & & $14(9.9)$ & $7(9.6)$ & \\
Others & $10(1-69)$ & $10(6-67)$ & $0.064^{*}$ & $10(3-32)$ & $10(6-67)$ & 0.111 \\
Postoperative days & $1003(39.1)$ & $18(22.2)$ & $0.002^{*}$ & $60(42.3)$ & $13(17.8)$ & $<0.001^{*}$ \\
All-cause mortality & $940(36.6)$ & $18(22.2)$ & $0.008^{*}$ & $58(45.7)$ & $13(18.8)$ & $<0.001^{*}$ \\
Cancer-specific mortality & & & & & & \\
\hline
\end{tabular}

$T B$, tuberculosis; NTB, non-tuberculosis; PSM, propensity-score matching ${ }^{*} P<0.05$, statistical significance

Table 3 Uni- and multivariate logistic regression analysis of PPCs 


\begin{tabular}{|c|c|c|c|c|}
\hline & \multicolumn{2}{|l|}{ Univariate } & \multicolumn{2}{|l|}{ Multivariate } \\
\hline & $\mathrm{HR}(95 \% \mathrm{Cl})$ & $P$-value & $\mathrm{HR}(95 \% \mathrm{Cl})$ & $P$-value \\
\hline \multicolumn{5}{|l|}{ Old TB } \\
\hline No & $1[$ Ref.] & & $1[$ Ref.] & \\
\hline Yes & $3.375(2.014-5.656)$ & $<0.001 *$ & $3.415(2.005-5.818)$ & $<0.001 *$ \\
\hline \multicolumn{5}{|l|}{ Gender } \\
\hline Male & $1[$ Ref.] & & $1[$ Ref.] & \\
\hline Female & $0.795(0.601-1.053)$ & 0.110 & $1.211(0.860-1.707)$ & 0.273 \\
\hline Age & $1.033(1.021-1.045)$ & $<0.001^{*}$ & $1.023(1.009-1.036)$ & $0.001^{*}$ \\
\hline \multicolumn{5}{|l|}{ ECOG } \\
\hline$<2$ & $1[$ Ref.] & & $1[$ Ref.] & \\
\hline$\geq 2$ & $1.667(1.100-2.526)$ & $0.016^{\star}$ & $1.145(0.734-1.787)$ & 0.551 \\
\hline \multicolumn{5}{|l|}{ Smoker } \\
\hline No & $1[$ Ref.] & & $1[$ Ref.] & \\
\hline Ex-smoker or current smoker & $1.370(1.068-1.758)$ & $0.013^{*}$ & $1.334(0.990-1.799)$ & 0.058 \\
\hline \multicolumn{5}{|l|}{ Comorbidity } \\
\hline No & $1[$ Ref.] & & $1[$ Ref.] & \\
\hline Pulmonary dysfunction & $1.877(1.403-2.511)$ & $<0.001^{\star}$ & $1.543(1.132-2.102)$ & $0.006^{*}$ \\
\hline Cardiac disease & $1.436(1.023-2.015)$ & $0.037^{*}$ & $1.116(0.777-1.603)$ & 0.552 \\
\hline Others & $1.582(1.125-2.226)$ & $0.008^{*}$ & $1.379(0.965-1.972)$ & 0.078 \\
\hline \multicolumn{5}{|l|}{ Blood transfusion } \\
\hline No & $1[$ Ref.] & & $1[$ Ref.] & \\
\hline Yes & $1.631(1.186-2.243)$ & $0.003^{*}$ & $1.322(0.942-1.854)$ & 0.106 \\
\hline \multicolumn{5}{|l|}{ Surgical procedure } \\
\hline Distal gastrectomy & $1[$ Ref.] & & $1[$ Ref.] & \\
\hline Total gastrectomy & $1.435(1.085-1.897)$ & $0.011 *$ & $0.877(0.555-1.387)$ & 0.575 \\
\hline Proximal gastrectomy & $1.751(1.226-2.501)$ & $0.002^{*}$ & $0.979(0.546-1.757)$ & 0.944 \\
\hline \multicolumn{5}{|l|}{ Location } \\
\hline Upper third & $1[$ Ref.] & & 1 [Ref.] & \\
\hline Middle third & $0.936(0.631-1.388)$ & 0.741 & $1.055(0.673-1.654)$ & 0.814 \\
\hline
\end{tabular}


Diffused

Histological grading

G1/G2

G3

$0.721(0.562-0.925)$

0.010 *

0.802(0.617-1.044)

0.101

$T B$, tuberculosis; NTB, non-tuberculosis; $H R$, hazard ratio; $C l$, confidence interval; Ref, reference; $E C O G$, Eastern Cooperative Oncology Group; G1, well differentiated; G2, moderately differentiated; G3, poorly differentiated; PPCs, postoperative pulmonary complications

${ }^{\star} P<0.05$, statistical significance

Table 4 Uni- and multivariate Cox regression analysis of overall survival before PSM 


\begin{tabular}{|c|c|c|c|c|c|c|}
\hline & Univaric & & & Multiva & ate & \\
\hline & HR & $95 \% \mathrm{Cl}$ & $P$-value & HR & $95 \% \mathrm{Cl}$ & $P$-value \\
\hline Old TB & & & & & & \\
\hline No & $1[$ Ref.] & & & 1[Ref.] & & \\
\hline Yes & 0.522 & $0.327-0.832$ & $0.006^{\star}$ & 0.471 & $0.294-$ & $0.002^{*}$ \\
\hline Age & 1.009 & $1.004-1.015$ & $0.001^{*}$ & 1.006 & & $0.048^{*}$ \\
\hline ECOG & & & & & 1.013 & \\
\hline$<2$ & $1[$ Ref.] & & & 1[Ref.] & & \\
\hline$\geq 2$ & 1.323 & $1.064-1.645$ & $0.012^{*}$ & 0.990 & & 0.935 \\
\hline Comorbidity & & & & & $\begin{array}{l}0.788- \\
1.244\end{array}$ & \\
\hline No & $1[$ Ref.] & & & 1[Ref.] & & \\
\hline $\begin{array}{l}\text { Pulmonary } \\
\text { dysfunctions }\end{array}$ & 1.200 & $1.019-1.412$ & $0.029 *$ & 1.212 & & $0.030 *$ \\
\hline Blood transfusion & $1[$ Ref.] & & & 1[Ref.] & $\begin{array}{l}1.019- \\
1.441\end{array}$ & \\
\hline TNO & 1.686 & $1.439-1.976$ & $<0.001^{*}$ & 1.183 & & $0.047^{*}$ \\
\hline Tumor size $(\mathrm{cm})$ & 1.192 & $1.173-1.212$ & $<0.001^{*}$ & 1.049 & & $<0.001 *$ \\
\hline Surgical procedure & 1 [Ref.] & & & 1[Ref.] & $\begin{array}{l}1.002- \\
1.397\end{array}$ & \\
\hline Distal gastrectomy & 1.975 & $1.720-2.268$ & $<0.001^{*}$ & 1.027 & $\begin{array}{l}1.021- \\
1.077\end{array}$ & 0.806 \\
\hline Proximal gastrectomy & 1.403 & $1.160-1.697$ & $<0.001^{*}$ & 1.219 & & 0.168 \\
\hline $\begin{array}{l}\text { Approach } \\
\text { Open qastrectomy }\end{array}$ & 1 [Ref.] & & & 1[Ref.] & $\begin{array}{l}0.828- \\
1.275\end{array}$ & \\
\hline LG/RAG & 0.636 & $0.512-0.789$ & $<0.001 *$ & 0.924 & $\begin{array}{l}0.920- \\
1.617\end{array}$ & 0.484 \\
\hline Location & 1[Ref.] & & & 1[Ref.] & & \\
\hline Middla third & 0.927 & $0.749-1.148$ & 0.487 & 1.013 & & 0.917 \\
\hline ower third & 0.736 & $0.635-0.853$ & $<0.001^{\star}$ & 0.959 & $0.740-$ & 0.733 \\
\hline Diffused & 2.926 & $2.145-3.991$ & $<0.001^{\star}$ & 1.516 & & $0.021^{*}$ \\
\hline Histological grading & 1[Ref.] & & & 1[Ref.] & & \\
\hline
\end{tabular}




\begin{tabular}{|c|c|c|c|c|c|c|}
\hline $\mathrm{G} 1 / \mathrm{G} 2$ & 1.527 & $1.330-1.752$ & $<0.001^{\star}$ & 1.094 & $\begin{array}{l}0.800- \\
1.281\end{array}$ & 0.235 \\
\hline G3 & & & & & $0.754-$ & \\
\hline Neural/vascular & $1[$ Ref.] & & & $1[$ Ref.] & 1.219 & \\
\hline Absent & 1.765 & $1.527-2.041$ & $<0.001^{\star}$ & 1.054 & $\begin{array}{l}1.063- \\
2.162\end{array}$ & 0.502 \\
\hline Present & $1[$ Ref.] & & & $1[$ Ref.] & & \\
\hline Bormann's type & 3.669 & $2.340-5.753$ & $<0.001^{\star}$ & 1.111 & & 0.645 \\
\hline Early-stage cancer & 3.968 & $3.014-5.225$ & $<0.001^{*}$ & 0.987 & $\begin{array}{l}0.943^{-} \\
1.269\end{array}$ & 0.920 \\
\hline Type & 5.926 & $4.508-7.790$ & $<0.001^{*}$ & 1.140 & & 0.287 \\
\hline Type III & 10.102 & 7.343-13.898 & $<0.001 *$ & 1.000 & & \\
\hline Type IV & 1[Ref.] & & & $1[$ Ref.] & $\begin{array}{l}0.905- \\
1.226\end{array}$ & \\
\hline pI & 2.407 & $1.741-3.326$ & $<0.001 *$ & 1.741 & & $0.010^{*}$ \\
\hline 11 & 3.188 & $2.362-4.303$ & $<0.001 *$ & 1.717 & O 710 & $0.011^{*}$ \\
\hline T3 & 7.320 & 5.605-9.558 & $<0.001^{*}$ & 2.554 & 1.739 & $<0.001^{*}$ \\
\hline $\mathrm{T} 4$ & 1[Ref.] & & & $1[$ Ref.] & $\begin{array}{l}0.764- \\
1.275\end{array}$ & \\
\hline $\mathrm{pN}$ & 2.111 & $1.650-2.700$ & $<0.001 *$ & 1.684 & $\begin{array}{l}0.896- \\
1.450\end{array}$ & $<0.001^{*}$ \\
\hline NO & 3.132 & 2.496-3.929 & $<0.001^{*}$ & 2.120 & & $<0.001^{*}$ \\
\hline$N 2$ & 5.615 & $4.553-6.924$ & $<0.001^{*}$ & 3.296 & & $<0.001^{*}$ \\
\hline N3a & 9.705 & $7.783-12.103$ & $<0.001^{*}$ & 4.556 & & $<0.001^{*}$ \\
\hline N3b & $1[$ Ref.] & & & $1[$ Ref.] & $\begin{array}{l}1.142- \\
2.656\end{array}$ & \\
\hline $\begin{array}{l}\text { Metastasis } \\
\text { M0 }\end{array}$ & 3.956 & $3.226-4.852$ & $<0.001^{\star}$ & 1.634 & $\begin{array}{l}1.134- \\
2.600\end{array}$ & $<0.001^{*}$ \\
\hline M1 & 1[Ref.] & & $<0.001$ * & & $\begin{array}{l}1.711- \\
3.812\end{array}$ & \\
\hline P-stage & 2.315 & $1.738-3.082$ & $<0.001^{*}$ & & & \\
\hline Stage I & 6.860 & $5.359-8.783$ & $<0.001^{\star}$ & & & \\
\hline $\begin{array}{l}\text { Stage II } \\
\text { Stage III }\end{array}$ & 15.332 & $\begin{array}{l}11.314- \\
20.778\end{array}$ & $<0.001 *$ & & $\begin{array}{l}1.305- \\
2.174\end{array}$ & \\
\hline Stage IV & & & & & $\begin{array}{l}1.659- \\
2.708\end{array}$ & \\
\hline
\end{tabular}




$\begin{array}{lcccccc}\text { POCs } & 1[\text { Ref.] } & & & 1[\text { Ref.] } & 2.595- & \\ \text { No } & 1.278 & 1.045-1.562 & 0.017^{*} & 1.306 & 4.186 & 0.012^{*} \\ \text { PPCs } & 1.318 & 1.084-1.602 & 0.006^{*} & 1.194 & 5.940 & 0.078\end{array}$

Others

Adjuvant

chemotherapy

No

$$
\text { 1[Ref.] }
$$

1[Ref.]

$\begin{array}{llll}0.625 & 0.546-0.715<0.001 * & 0.610\end{array}$

Yes

$T B$, tuberculosis; NTB, non-tuberculosis; $H R$, hazard ratio; $C l$, confidence interval; Ref, reference; $E C O G$, Eastern Cooperative Oncology Group; $L G$, laparoscopic gastrectomy; $R A G$, robot-assisted gastrectomy; $G 1$, well differentiated; $G 2$, moderately differentiated; $G 3$, poorly differentiated

${ }^{*} P<0.05$, statistical significance

Table 5 Uni- and multivariate Cox regression analysis of overall survival after PSM 


\begin{tabular}{|c|c|c|c|c|c|c|}
\hline \multirow{3}{*}{ Old TB } & \multicolumn{3}{|c|}{ Univariate } & \multicolumn{3}{|c|}{ Multivariate } \\
\hline & \multirow[t]{2}{*}{ HR } & \multirow[t]{2}{*}{$95 \% \mathrm{Cl}$} & \multirow[t]{2}{*}{$P$-value } & \multirow[t]{2}{*}{ HR } & \multirow[t]{2}{*}{$95 \% \mathrm{Cl}$} & \multirow[t]{2}{*}{$P$-value } \\
\hline & & & & & & \\
\hline No & 1[Ref.] & & & $1[$ Ref.] & & \\
\hline Yes & 0.364 & $0.199-0.664$ & $0.001 *$ & 0.220 & $0.107-0.454$ & $<0.001 *$ \\
\hline Age & 1.001 & $0.979-1.024$ & 0.911 & 1.010 & $0.981-1.039$ & 0.516 \\
\hline \multicolumn{7}{|l|}{ ECOG } \\
\hline$<2$ & 1[Ref.] & & & $1[$ Ref.] & & \\
\hline$\geq 2$ & 1.187 & $0.607-2.319$ & 0.617 & 1.099 & $0.439-2.749$ & 0.840 \\
\hline \multicolumn{7}{|l|}{ Comorbidity } \\
\hline No & 1[Ref.] & & & $1[$ Ref.] & & \\
\hline $\begin{array}{l}\text { Pulmonary } \\
\text { dysfunctions }\end{array}$ & 0.992 & $0.561-1.755$ & 0.979 & 1.081 & $0.510-2.288$ & 0.840 \\
\hline Blood transfusion & 1[Ref.] & & & $1[$ Ref.] & & \\
\hline Voe & 1.931 & $1.106-3.369$ & $0.021^{\star}$ & 1.037 & $0.476-2.255$ & 0.928 \\
\hline Tumor size(cm) & 1.181 & $1.118-1.248$ & $<0.001^{*}$ & 1.047 & $0.944-1.161$ & 0.385 \\
\hline Surgical procedure & 1[Ref.] & & & $1[$ Ref.] & & \\
\hline Distal gastrectomy & 1.951 & $1.160-3.281$ & $0.012^{\star}$ & 0.391 & $0.114-1.338$ & 0.135 \\
\hline Proximal gastrectomy & 1.256 & $0.652-2.420$ & 0.497 & 0.147 & $0.033-0.661$ & $0.012^{*}$ \\
\hline Approach & 1[Ref.] & & & 1[Ref.] & & \\
\hline LG/RAG & 0.471 & $0.204-1.087$ & $0.078^{*}$ & 0.238 & $0.088-0.645$ & $0.005^{\star}$ \\
\hline Location & 1[Ref.] & & & $1[$ Ref.] & & \\
\hline Middla third & 0.619 & $0.278-1.378$ & 0.240 & 0.288 & $0.096-0.868$ & $0.027 *$ \\
\hline Lower third & 0.503 & $0.299-0.846$ & $0.010^{\star}$ & 0.112 & $0.029-0.428$ & $0.001 *$ \\
\hline Diffused & 7.936 & $\begin{array}{l}2.620- \\
24.037\end{array}$ & $<0.001 *$ & 2.357 & $\begin{array}{l}0.427- \\
13.005\end{array}$ & 0.325 \\
\hline Histological grading & $1[$ Ref.] & & & $1[$ Ref.] & & \\
\hline
\end{tabular}


G1/G2

G3

Neural/vascular

invasion

Absent

Present

Bormann's type

Early-stage cancer

Type I

Type II

Type III

Type IV

pT

T1

$\mathrm{T} 2$

T3

$\mathrm{T} 4$

$\mathrm{pN}$

NO

N1

N2

N3a

N3b

Metastasis

MO

M1

P-stage

Stage I

Stage II

Stage III

Stage IV
0.813

0.388

0.508-1.301

1[Ref.]

1.793

$1.067-3.012$

1[Ref.]

1.127

3.100

$0.234-5.430$

0.881

3.738

1.341-7.169

$0.008^{*}$

$0.002 *$

8.001

1.626-8.595

$<0.001^{\star}$ 3.042-

21.043

1[Ref.]

1.947

1.627

5.852

$0.755-5.023$

0.590-4.486

0.168

0.347

$<0.001^{*}$

2.636-

1 [Ref.] 12.993

0.956

1.296

2.803

$0.421-2.171$

4.955

$0.621-2.705$

1.507-5.215

1[Ref.] 2.409-

4.792

10.189

0.914

0.490

0.001 *

$<0.001^{\star}$

2.092

$0.379-2.274$

$0.743-4.774$

1[Ref.] $\quad 0.652-6.714$

$<0.001^{*}$

2.120

0.491

$0.641-2.526$

1[Ref.]

0.166

0.076

$0.839 \quad 0.023-1.206$

0.770

$0.943 \quad 0.258-2.732$

0.917

$1.000 \quad 0.311-2.859$

1[Ref.]

2.359

0.276

1.353

$0.504-$

11.046

0.698

0.293-6.245

0.139

$0.684-$

15.391

0.790

0.641

0.928

0.871

$1.884 \quad 0.294-2.125$

0.182

0.215

1[Ref.]

2.563-8.959

0.878-5.119
1.805

3.106

9.278

$0.852-3.823$

1.556-6.201
$0.123^{*}$

0.001 *

$<0.001^{*}$ 


\begin{tabular}{|c|c|c|c|c|c|c|}
\hline POCs & $1[$ Ref.] & \multirow{2}{*}{$\begin{array}{l}4.073- \\
21.135\end{array}$} & & \multicolumn{2}{|l|}{ 1[Ref.] } & \multirow[b]{2}{*}{$0.005^{\star}$} \\
\hline No & 1.879 & & $0.021^{\star}$ & 2.531 & & \\
\hline PPCs & 0.818 & & 0.644 & 1.094 & & 0.860 \\
\hline Others & & \multirow{3}{*}{$\begin{array}{l}1.100-3.209 \\
0.349-1.918\end{array}$} & & & $1.319-4.860$ & \multirow{5}{*}{$0.018 *$} \\
\hline Adjuvant chemotherapy & $1[$ Ref.] & & & $1[$ Ref.] & $0.401-2.989$ & \\
\hline No & 0.467 & & $0.004^{\star}$ & 0.495 & & \\
\hline \multirow[t]{2}{*}{ Yes } & & & & & & \\
\hline & & $0.278-0.783$ & & & $0.276-0.887$ & \\
\hline
\end{tabular}

$T B$, tuberculosis; NTB, non-tuberculosis; $H R$, hazard ratio; $C l$, confidence interval; Ref, reference; $E C O G$, Eastern Cooperative Oncology Group; $L G$, laparoscopic gastrectomy; $R A G$, robot-assisted gastrectomy; $G 1$, well differentiated; $G 2$, moderately differentiated; $G 3$, poorly differentiated

$* P<0.05$, statistical significance

\section{Figures}




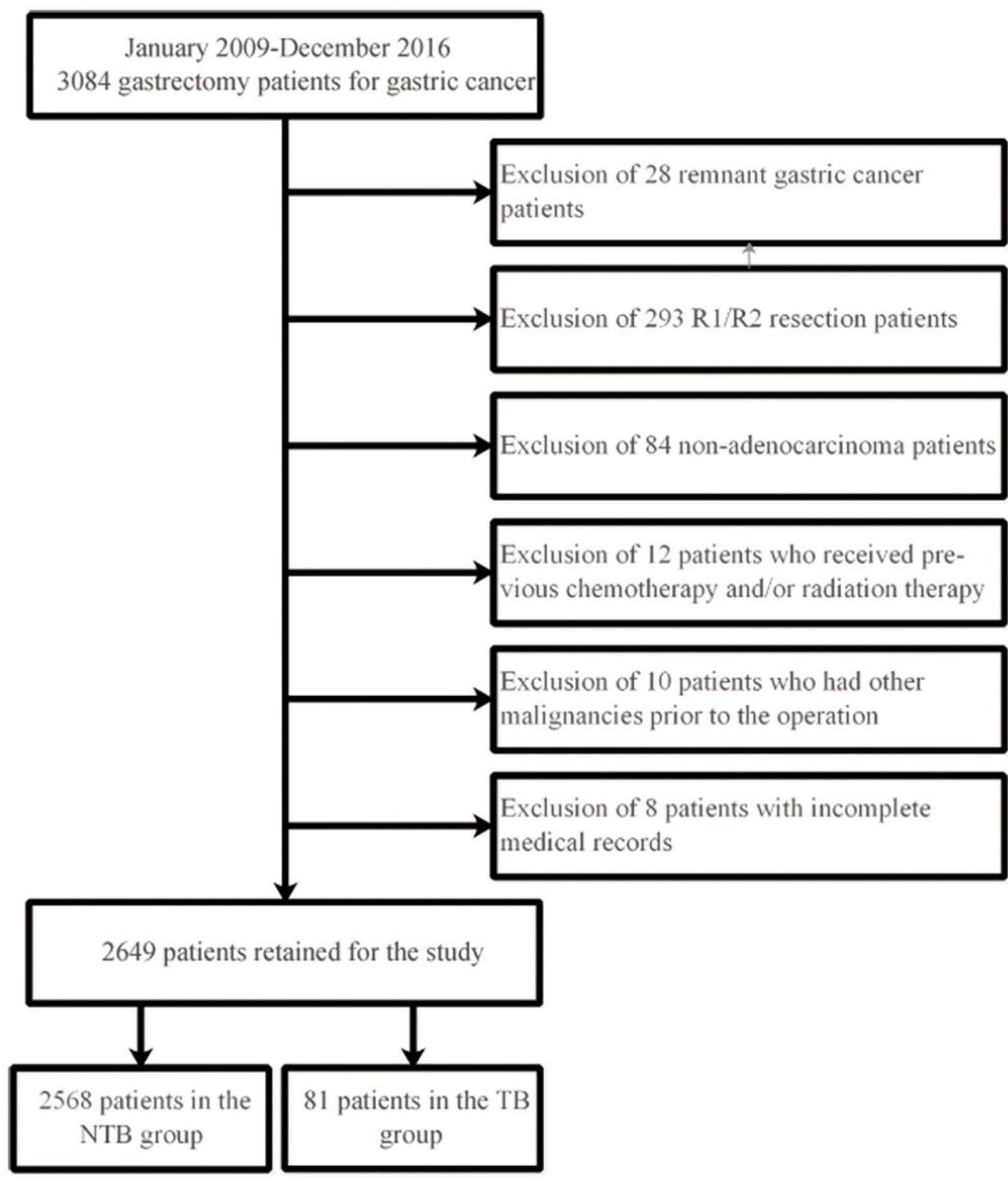

Figure 1

Flowchart for the cohort study. NTB group: Non-Tuberculosis group; TB group: Tuberculosis group 
Fig.2

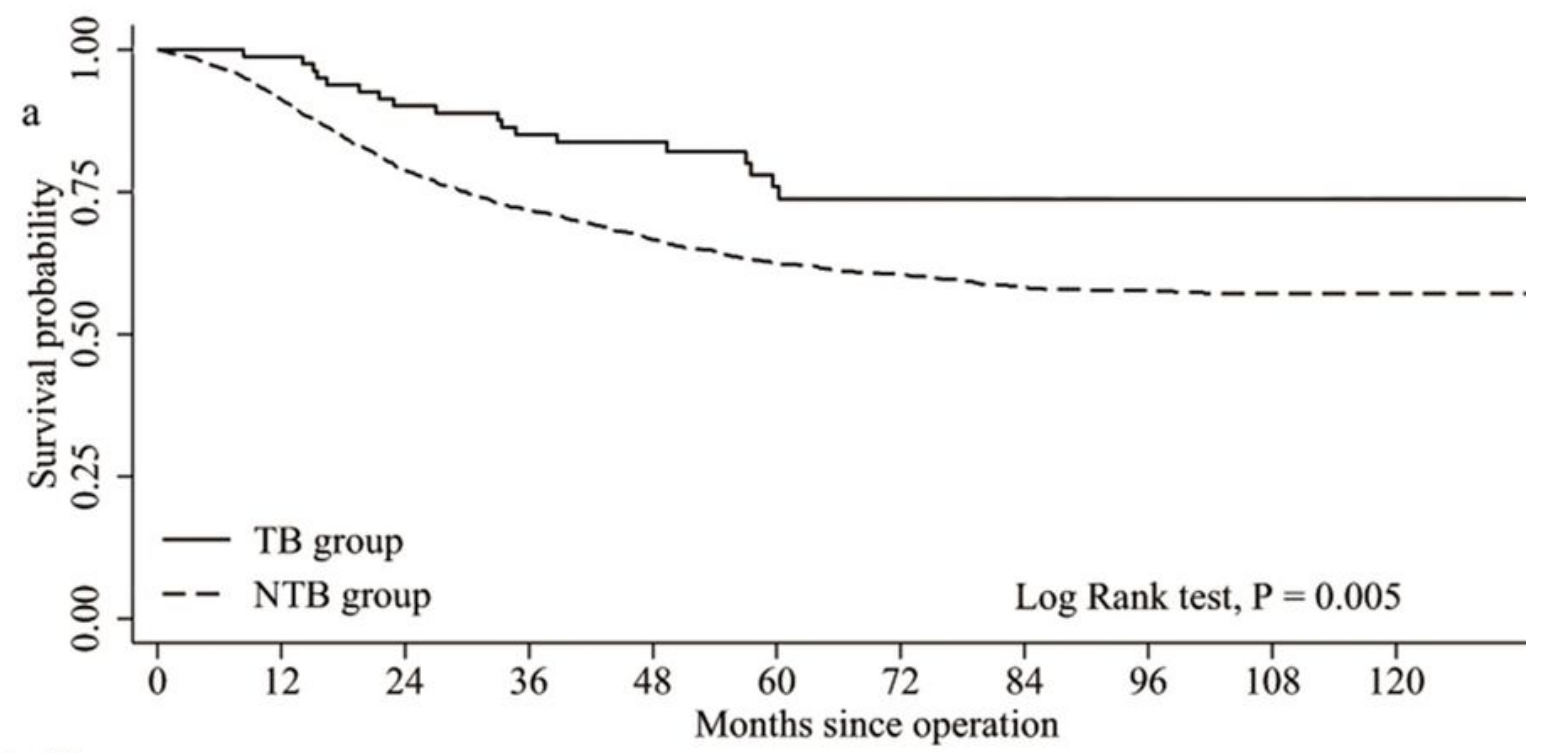

$\begin{array}{rccccccccccc}\text { Number at risk } & & & & & & & & & & \\ \text { NTB group } & 2568 & 2276 & 1890 & 1656 & 1339 & 1046 & 781 & 561 & 361 & 205 & 100 \\ \text { TB group } & 81 & 80 & 73 & 68 & 49 & 36 & 28 & 21 & 16 & 11 & 5\end{array}$

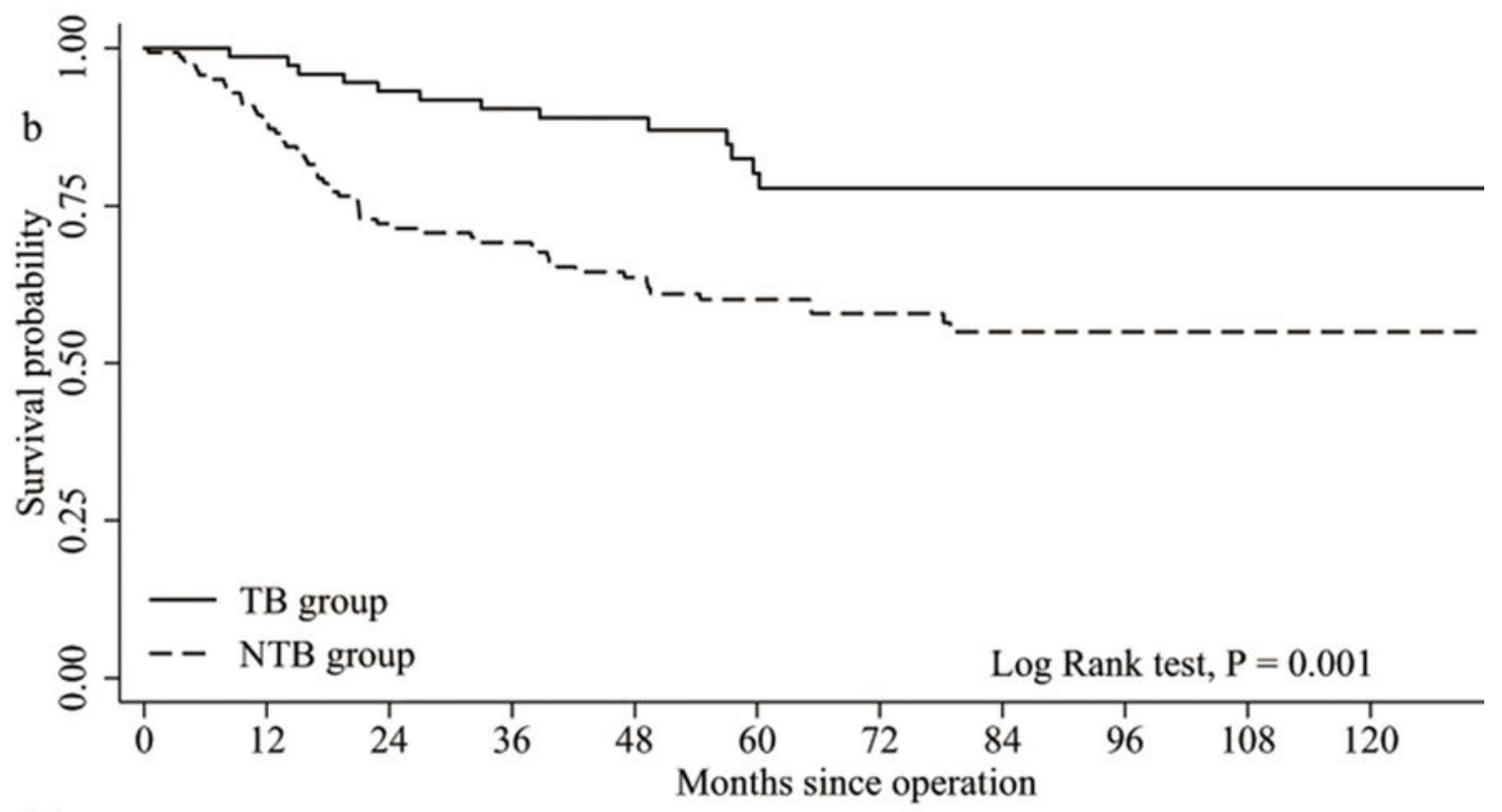

Number at risk

$\begin{array}{rccccccccccc}\text { NTB group } & 142 & 124 & 99 & 94 & 73 & 58 & 46 & 33 & 23 & 13 & 8 \\ \text { TB group } & 73 & 72 & 68 & 65 & 47 & 34 & 26 & 20 & 15 & 11 & 5\end{array}$

Figure 2

Kaplan-Meier curves demonstrating overall survival (OS) of (a) all the patients and (b) the matched patients between the TB group and NTB group TB, tuberculosis; NTB, non-tuberculosis 